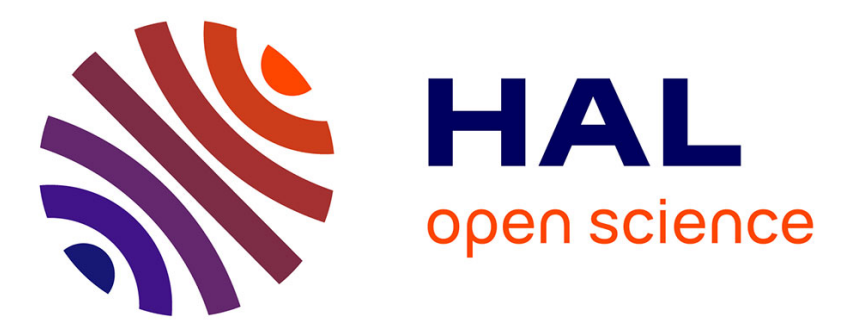

\title{
Fault Prognostics for the Predictive Maintenance of Wind Turbines: State of the Art
}

\author{
Koceila Abid, Moamar Sayed Mouchaweh, Laurence Cornez
}

\section{To cite this version:}

Koceila Abid, Moamar Sayed Mouchaweh, Laurence Cornez. Fault Prognostics for the Predictive Maintenance of Wind Turbines: State of the Art. Joint European Conference on Machine Learning and Knowledge Discovery in Databases - ECML PKDD 2018, Sep 2018, Dublin, Ireland. pp.113-125, 10.1007/978-3-030-14880-5_10. cea-02174945

\section{HAL Id: cea-02174945 https://hal-cea.archives-ouvertes.fr/cea-02174945}

Submitted on 5 Jul 2019

HAL is a multi-disciplinary open access archive for the deposit and dissemination of scientific research documents, whether they are published or not. The documents may come from teaching and research institutions in France or abroad, or from public or private research centers.
L'archive ouverte pluridisciplinaire HAL, est destinée au dépôt et à la diffusion de documents scientifiques de niveau recherche, publiés ou non, émanant des établissements d'enseignement et de recherche français ou étrangers, des laboratoires publics ou privés. 


\title{
Fault Prognostics for the Predictive Maintenance of Wind Turbines: State of the Art
}

\author{
Koceila ABID ${ }^{1,2}$, Moamar SAYED MOUCHAWEH ${ }^{1}$, and Laurence CORNEZ ${ }^{2}$ \\ 1 IMT Lille Douai, Lille University, France \\ koceila.abid@imt-lille-douai.fr \\ moamar.sayed-mouchaweh@imt-lille-douai.fr \\ 2 CEA LIST, DM2I, LADIS, France \\ koceila.abid@cea.fr \\ laurence.cornez@cea.fr
}

\begin{abstract}
Reliability and availability of wind turbines are crucial due to several reasons. On the one hand, the number and size of wind turbines are growing exponentially. On the other hand, installation of these farms at remote locations, such as offshore sites where the environment conditions are favorable, makes maintenance a more tedious task. For this purpose, predictive maintenance is a very attractive strategy in order to reduce unscheduled downtime and maintenance cost. Prognostic is an online technique that can provide valuable information for proactive actions such as the current health state and the Remaining Useful Life (RUL). Several fault prognostic works have been published in the literature. This paper provides an overview of the different prognostic phases, including: health indicator construction, degradation detection, and RUL estimation. Different prognostic approaches are presented and compared according to their requirements and performance. Finally, this paper discusses the suitable prognostic approaches for the proactive maintenance of wind turbines, allowing to address the latter challenges.
\end{abstract}

Keywords: Fault prognostics $\cdot$ Remaining useful life $\cdot$ Predictive maintenance $\cdot$ Wind turbines.

\section{Introduction}

The production of electricity using wind energy has an increasing trend in the last decade especially in Europe. It is reported in [1] that the wind energy has become the second source of energy in Europe behind the gas. This trend entails a growing evolution in the number and size of wind turbines (WTs), which lead to increase the cost of Operation and Maintenance (O\&M). The cost of O\&M for one wind turbine is about $20-30 \%$ of overall lifetime costs of energy.

Traditional maintenance strategies such as curative maintenance or preventive maintenance have a main drawback that is the fault is undergone by the system. Prognostics and Health Management (PHM) or predictive maintenance provides an advanced maintenance strategy that can enhance the reliability and 
availability while reducing unscheduled fault and maintenance cost of systems such as WT. Health monitoring of WTs is achieved by monitoring the performance of the WT (e.g., power curve)[10] or condition monitoring of components, in particular critical components as rotating machinery (e.g., generator). Fault prognostic is an important step of the predictive maintenance. It can be defined as the prediction of when a failure might take place or the estimation of the Remaining Useful Life (RUL), which is the time between degradation detection and failure threshold. It is an online technique that can provide valuable information for proactive actions allowing mitigating the fault consequences and/or scheduling maintenance steps. RUL prediction of critical components is a very challenging task due to sensor noise, complexity of the system, and prediction uncertainty caused by the switch between operating conditions, and environment variability (e.g., wind speed and direction).

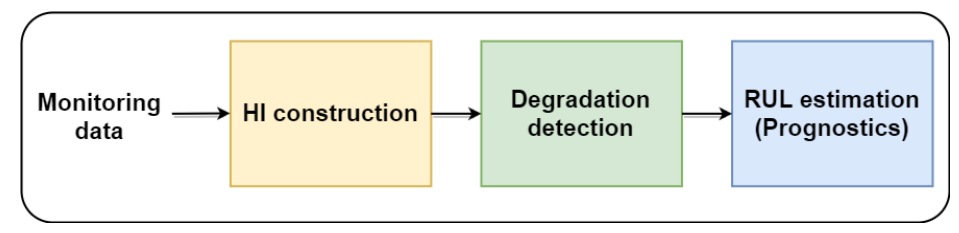

Fig. 1: General approach of prognostic.

The general approach of prognostic is presented in Fig. 1. It indicate the three main steps of prognostics: Health Indicator (HI) construction, Degradation detection and RUL estimation. First the HI is constructed by processing monitoring data in order to monitor the evolution of system performance over time. The second step is the degradation detection triggered as soon as the HI goes below a predefined threshold. The third step is the aims at predicting the degradation evolution and estimating the time when the system will go below a failure threshold. In this review, the techniques used to perform the different steps of the prognostic approach are presented and compared in terms of requirements and performances within the context of wind turbines predictive maintenance. The suitable prognostic approaches for the proactive maintenance of wind turbines are discussed, allowing to address the latter challenges.

\section{Health indicator construction}

Health Indicator (HI) construction is the main step for achieving prognostic. It represents the evolution over time of the system performance. When this evolution is decreasing, this indicates a drift from normal or nominal operation conditions towards a failure. Concept drift techniques can be used to monitor the performance of systems by learning patterns from data streams gathered by sensors [20], where a new class is detected if there is a decrease in the system 
performance according to its nominal value. HIs can be classified in two categories : physics health indicators and virtual health indicators which cannot be interpreted with physical sense. They can also be classified into HI based on a single feature such as using the raw data gathered from sensors, residuals based feature, time domain or time-frequency feature extracted from data measured by monitoring sensors. The second kind of HI is based on a fusion of multiple features that can perform better representation of the system health.

Single feature based HI is based on a single extracted feature which can be more interpretable. Most of prognostic works for wind turbine focused on the condition monitoring of WT rotating machine (e.g., low and high speed shaft, gearbox, generator) due to its criticity. Condition monitoring for such systems is achieved by using vibration signal, acoustic emission, oil analysis or current signal analysis. In the case of complex degradations, it is often hard to find one feature sensitive to those degradations. Therefore, it is unfeasible to construct a $\mathrm{HI}$ able to follow in the degradation evolution over time and to allow a reliable estimation of RUL. In order to tackle this problem, a solution is to fuse several features in order to exploit their complementarity. However, this fusion entails the lose of physics meaning (e.g., dimension reduction or distance between class in a feature space). This lose leads to a lack of $\mathrm{HI}$ interpretability so it represents a virtual description of the system performance health.

Several methods of HI construction based on a single and multiple features are proposed in the literature, which are summarized in Table. 1.

\subsection{Health indicator evaluation}

HIs are evaluated using different criteria presented in [11]. The most pertinent HI evaluation criteria are monotonicity and trendability[18][9][36].

Monotonicity The monotonicity evaluate the negative or positive trend of the HI, with the assumption that the system cannot self-heal [9][18]. Monotonicity can be measured by the absolute difference between negative and positive derivative of $\mathrm{HI}$ as indicated in the following equation :

$$
M=\left|\frac{\text { Number of }(d / d x>0)}{n-1}-\frac{\text { Number of }(d / d x<0)}{n-1}\right|, M \in[0 ; 1]
$$

where $d / d x$ represents the derivative of the HI, $n$ represents the number of observations, $M$ represents a higher monotonicity of a degradation when it approaches 1.

Trendability Trendability is related to time and represents the correlation between the degradation trend and the operating time of a component[9], and can be calculated as follow :

$$
R=\frac{n\left(\sum_{i=1}^{n} x_{i} t_{i}\right)-\left(\sum_{i=1}^{n} x_{i}\right)\left(\sum_{i=1}^{n} t_{i}\right)}{\sqrt{\left[n \sum_{i=1}^{n} x_{i}^{2}-\left(\sum_{i=1}^{n} x_{i}\right)^{2}\right]\left[n \sum_{i=1}^{n} t_{i}^{2}-\left(\sum_{i=1}^{n} t_{i}\right)^{2}\right]}}
$$


Table 1: Health indicator construction methods.

\begin{tabular}{|c|c|c|c|}
\hline $\begin{array}{l}\text { Feature } \\
\text { type }\end{array}$ & $\begin{array}{l}\text { Computation } \\
\text { approaches }\end{array}$ & Methods & Data \\
\hline \multirow{8}{*}{$\begin{array}{l}\text { Single } \\
\text { feature } \\
\text { based HI }\end{array}$} & \multirow{4}{*}{$\begin{array}{l}\text { Raw signal and } \\
\text { residuals }\end{array}$} & $\begin{array}{l}\text { Raw signal of viscosity and dielec- } \\
\text { tric constant }[37][38]\end{array}$ & Lubrication oil (gearbox) \\
\hline & & Raw signal of oil debris $[6]$ & Lubrication oil (gearbox) \\
\hline & & Power residual[28] & Generated power signal \\
\hline & & Temperature residual[2] & Bearings temperature (Gearbox) \\
\hline & \multirow{3}{*}{$\begin{array}{l}\text { Time domain } \\
\text { features }\end{array}$} & Root mean square $[12][13]$ & Vibration (bearings) \\
\hline & & Spectral kurtosis [22] & Vibration (bearings) \\
\hline & & Trigonometric functions [9] & Vibration (bearings) \\
\hline & $\begin{array}{l}\text { Time-frequency } \\
\text { features }\end{array}$ & $\begin{array}{l}\text { Wavelet Packet Decomposition } \\
{[24]}\end{array}$ & Vibration (bearings) \\
\hline \multirow{6}{*}{$\begin{array}{l}\text { Multiple } \\
\text { features } \\
\text { based HI }\end{array}$} & & Hilbert huang transform [18] & Vibration (bearings) \\
\hline & & Power spectral density [5] & Current signal (gearbox) \\
\hline & \multirow{2}{*}{$\begin{array}{l}\text { Dimension } \\
\text { reduction }\end{array}$} & $\operatorname{ISOMAP}[3][23]$ & Vibration (bearings) \\
\hline & & $\mathrm{PCA}[32]$ & SCADA data \\
\hline & \multirow[t]{2}{*}{$\begin{array}{l}\text { Distance } \\
\text { between classes }\end{array}$} & $\begin{array}{l}\text { Euclidian and mahalanobis dis- } \\
\text { tance }[25][26]\end{array}$ & $\begin{array}{l}\text { Pitch angle (pitch system), Volt- } \\
\text { age (Converter) }\end{array}$ \\
\hline & & Jensen-Renyi Distance [4] & Vibration (bearings) \\
\hline
\end{tabular}

$R \in[-1 ; 1]$ represents the correlation coefficient between indicator $x$ and the time index $t$. $R$ approaches 1 , when the HI has a strong positive linear correlation with time.

\section{Degradation detection based on health stage division}

The computed HI gives information about the system health (condition and performance). When a degradation occurred (drift from normal condition or nominal performance) the HI presents an increasing or decreasing trend. Then prognostic module can start because RUL prediction when no fault occurred is unnecessary. The degradation can be detected by dividing the HI into two or multiple stages using a threshold according to the degradation trend. Dividing the health stage using a threshold is widely used in the literature for this task, some works used classification techniques when sufficient degradation data are available in order to estimate the boundary between nominal and degraded conditions (see Table. 2). Multiple stage division by considering an intermediate stage is also important in order to confirm the degradation occurrence with a second threshold for avoiding false alarms. 
Table 2: Degradation detection methods.

\begin{tabular}{llll}
\hline Approaches & Methods & Advantage & Drawback \\
\hline Threshold & $\begin{array}{l}\text { Threshold } \\
\text { value[15] }\end{array}$ & $\begin{array}{l}\text { No need for degradation data. Easy } \\
\text { for implementation. }\end{array}$ & $\begin{array}{l}\text { Difficulty to choose the threshold } \\
\text { value in order to achieve early } \\
\text { degradation detection and avoid } \\
\text { false alarms. Need of an expert for } \\
\text { the choice of the threshold value. }\end{array}$ \\
& $\begin{array}{l}\text { Statistical } \\
\text { threshold } \\
3 \sigma \text { interval } \\
{[33]}\end{array}$ & & \\
\hline Classification & $\begin{array}{l}\text { Logistic } \\
\text { regression } \\
{[34]}\end{array}$ & $\begin{array}{l}\text { The boundary between nominal Necessity of system degradation } \\
\text { and degraded conditions is esti- data. Model parameters are diffi- } \\
\text { mated automatically. }\end{array}$ & \\
SVM $[22]$ & &
\end{tabular}

The goal of this division is to 1) identify the stages where the degradation process is active and 2) separate the degradation progress or evolution over time according to its dynamics (fast, slow, decreasing or self-healing, increasing and stable etc.). This division allows to improve the reliability of degradation detection and the RUL estimation.

\section{Fault prognostic (RUL estimation)}

Prognostic aims at estimating the remaining useful life of a component using the built HI. RUL estimation starts when a degradation is detected (drift from the nominal performance). Generally, RUL is estimated based on the use of one of the following two main approaches: Experience based approaches and degradation modeling approaches(see Fig. 2). Experience based prognostic is achieved by applying reliability or similarity based approaches. The degradation modeling can be achieved by using physical models or by data-driven approaches.

\subsection{Experience based prognostic}

Experience based prognostics methods are based on the use of maintenance or inspection feedback data sets gathered during a significant period of time. They represent the operational conditions during all the degradation process until the failure. In general, they can be classified into reliability based and similarity based approaches. Reliability based approaches employ a statistical failure distribution (i.e., Weibull) in order to fit to the gathered data. A periodic update of the parameters of this failure distribution is performed in order to adjust those parameters according to the experience obtained from the current maintenance practices. The built failure distribution is used for the RUL estimation of components with similar characteristics. Similarity based approaches use a library of degradation patterns for a set of components under different operation 


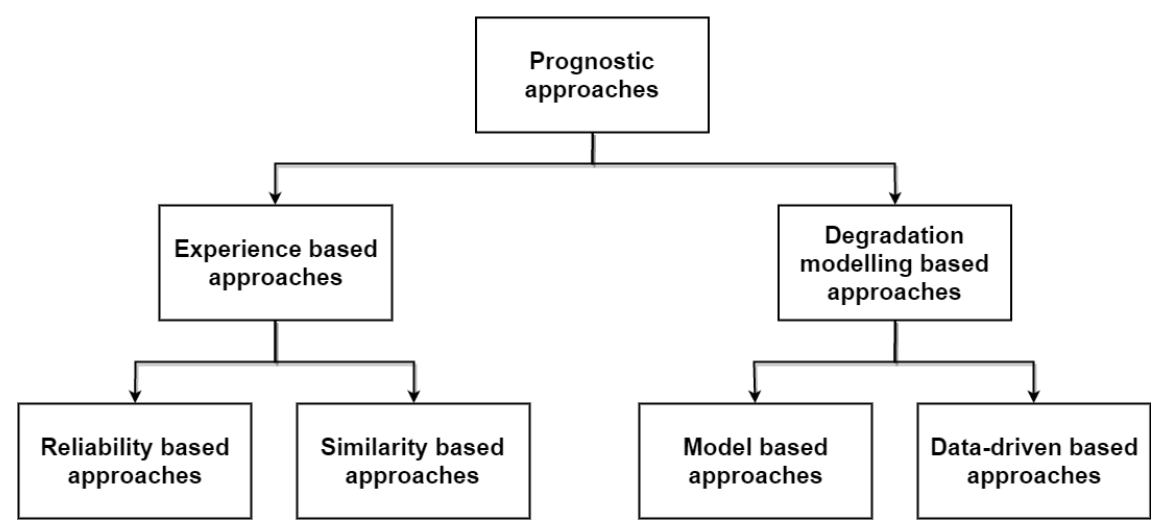

Fig. 2: RUL estimation approaches.

conditions. Each degradation pattern represents the degradation development of a component under certain operation conditions until the failure. The data gathered about the operation conditions of a component during a time window is compared to the degradation patterns in order to select the one who fits the best the data within this time window. Then, the RUL is estimated using the selected degradation pattern. Table. 3 summarizes some experience based approaches presented in the literature for the prognostics.

Table 3: Experience based approaches.

\begin{tabular}{|c|c|c|c|c|}
\hline Approaches & Methods & Application & Advantage & Drawback \\
\hline $\begin{array}{l}\text { Reliability } \\
\text { based } \\
\text { approach }\end{array}$ & $\begin{array}{l}\text { Weibull } \\
\text { distribution } \\
{[21][35]}\end{array}$ & Engine & $\begin{array}{l}\text { Can monitor the system } \\
\text { health state only with the } \\
\text { operating cycle of the sys- } \\
\text { tem. }\end{array}$ & $\begin{array}{l}\text { Depends on degradation his- } \\
\text { tory. Not adapted for com- } \\
\text { plex systems due several in- } \\
\text { teracting components and } \\
\text { varying conditions. Less pre- } \\
\text { cise without using monitor- } \\
\text { ing data. }\end{array}$ \\
\hline \multirow[t]{3}{*}{$\begin{array}{l}\text { Similarity } \\
\text { based } \\
\text { approach }\end{array}$} & $\begin{array}{l}\text { Similarity } \\
\text { distance } \\
{[29][30]}\end{array}$ & $\begin{array}{l}\text { Electric cool- } \\
\text { ing fan, engi- } \\
\text { neered system }\end{array}$ & $\begin{array}{l}\text { Good precision at compo- } \\
\text { nent level if suitable data } \\
\text { history is available. monitor } \\
\text { the current health state of } \\
\text { the system. }\end{array}$ & $\begin{array}{l}\text { Depends on degradation his- } \\
\text { tory. Not adapted for com- } \\
\text { plex systems due several in- } \\
\text { teracting components and } \\
\text { varying conditions. }\end{array}$ \\
\hline & $\begin{array}{l}\text { KNN } \\
{[14][17]}\end{array}$ & $\begin{array}{l}\text { Battery, } \\
\text { turbofan, } \\
\text { engineered } \\
\text { system }\end{array}$ & & \\
\hline & $\begin{array}{l}\text { Fuzzy } \\
\text { similarity } \\
{[39]}\end{array}$ & Reactor & & \\
\hline
\end{tabular}


Experience-based prognostics methods are efficient when degradation history is available for a system during a long period. The degradation history must represent the health evolution of the system from the healthy state until the failure state (run to failure). Reliability based approaches are not suitable for components showing complex degradation behaviour according to the operation and environment conditions. This is due to the fact that they do not use the online operation data in order to estimate the RUL. Similarity based approaches require also run to failure data history of identical units or components. Comparing to reliability approaches, similarity based approaches use online monitoring data in order to compare it with degradation history and estimate the RUL. They have the advantage to be easy to implement and precise at the level of components if the latter present the same degradation trend. However, they are not adapted for complex systems due to the varying operation and environment conditions.

\subsection{Degradation modelling based approaches}

This category of approaches aims at predicting the degradation evolution over time in order to estimate the system failure (end of life), Then the RUL is computed as the time from degradation detection until the failure. Model based approaches use physical and mathematical relations in order to model the degradation trend. These methods are usually used at component level and deal with wearing, crack, and corrosion phenomena. Paris law [16] is the most physics model used for the prediction of wear on rolling element bearing. Data driven approaches transform monitoring data gathered from sensors into relevant information about the system behaviour and dynamics, the mainly used methods are statistical and artificial Intelligence (AI) tools. Statistical techniques estimate the RUL of systems based on empirical knowledge, where artificial intelligence techniques are based on two phases: offline learning phase and online test phase. The model uses a database for training parameters in the offline phase, after that the online phase estimates the current health state of the system and predict its future state (evolution) over time. these methods are increasingly used due to their ability to find relation between data by training the model using datasets. Degradation modelling methods used in the literature are summarized in Table. 4.

Degradation modeling approaches use online monitoring data in order to observe the current health state of the system. Degradation evolution prediction is allowed when degradation of the system is detected. Model based degradation approaches are used generally at component level prognostic, where they gives more precision but they require extensive experimentation and model verification. These models are reliable when the system state have not been changed or upgraded. The models can be interpreted because its parameters are extracted from the system physics. However, it is difficult to generate degradation behaviour especially for complex system where several phenomena take place into the system. Data-driven based approaches are considered as black box models where the relation between input and output is complex and is hard for interpretation, but they can be used when the system is complex and where developing 
Table 4: Degradation modeling approaches.

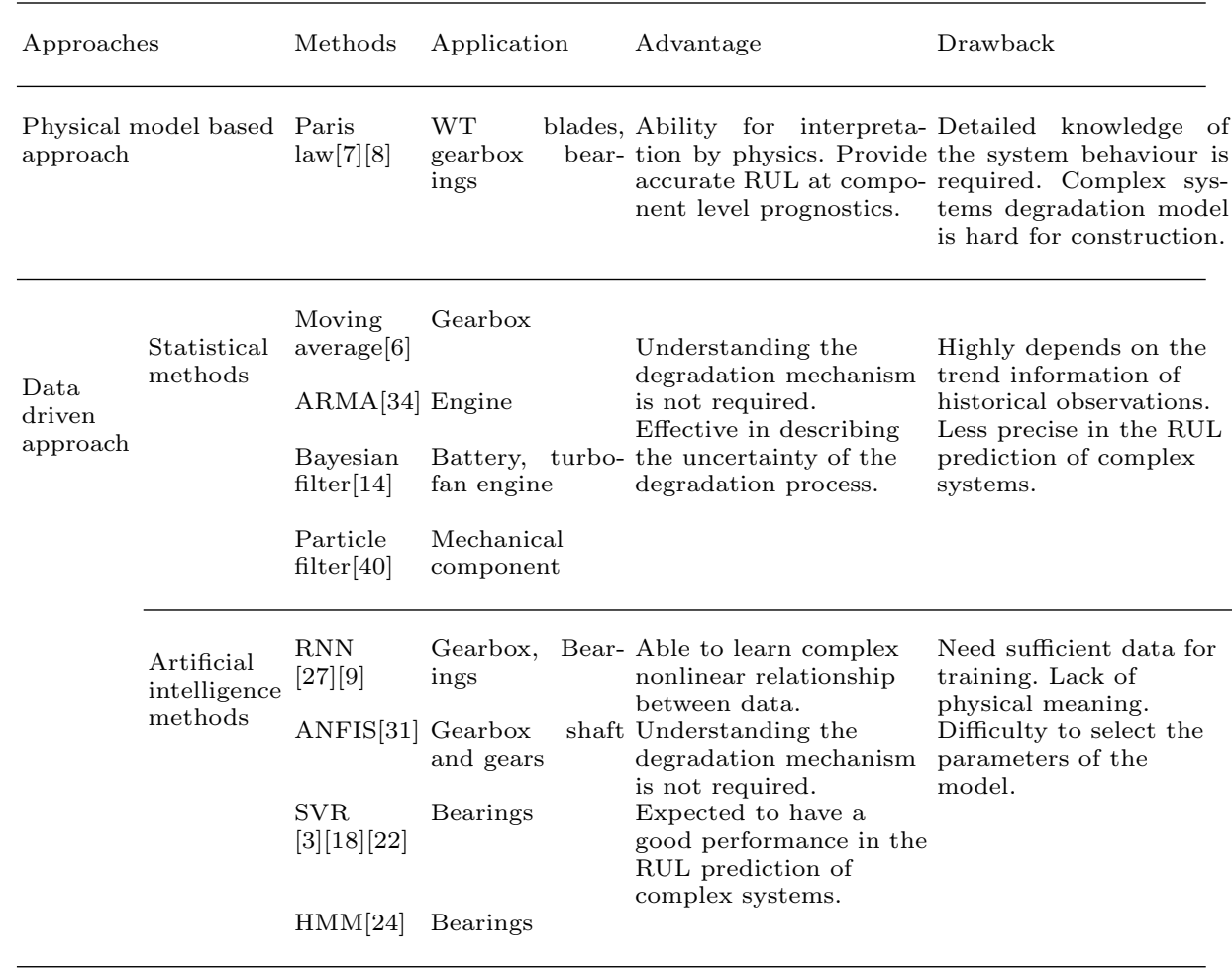

an accurate physical or mathematical model is not feasible. At component level, they can be less precise than the model based approaches, However, they are more suitable and efficient for complex systems whose degradation process is too hard to be modeled and represented by physical models.

\section{Prognostic metrics}

When the RULs are predicted online for each sample of time, RULs must be evaluated using suitable and meaningful metrics. Root Mean Square Error (RMSE) and Mean Absolute Percentage Error (MAPE) are widely used in the literature for RUL evaluation depending on the true RUL.

$$
\begin{gathered}
R M S E=\sqrt{\frac{1}{n} \sum_{t=1}^{n}\left(r^{l}(t)-r_{*}^{l}(t)\right)^{2}} \\
M A P E=\frac{100 \%}{n} \sum_{t=1}^{n}\left|\frac{r^{l}(t)-r_{*}^{l}(t)}{r^{l}(t)}\right|
\end{gathered}
$$


Where $n$ is the number of observations, $t$ is the time index, $r_{*}^{l}$ represents the true RUL, and $r^{l}$ represents the predicted RUL.

In [19], new metrics for prognostics performance evaluation are proposed. The most relevant metrics are : Prognostic Horizon, $\alpha-\lambda$ Performance, Relative Accuracy, and Cumulative Relative Accuracy. Prognostic Horizon (PH) is the difference between the current time index when the degradation is detected and the time of end of life (EoL). $\alpha-\lambda$ performance can determine whether the prediction falls within specified limits at particular times. Relative prediction accuracy is the errors between the predicted RUL relative to the actual (true) RUL at a specific time index. Cumulative Relative Accuracy CRA evaluates the RUL at multiple time instances. CRA is computed as the weighted sum of relative accuracies at multiple time instances.

\section{Conclusion}

The paper presents an overview of fault prognostic approaches for the monitoring and predictive maintenance of WTs. The fault prognostics of WTs is a challenging task because of their dynamics complexity, their different operating conditions, and the strong variability of their environment. The discussed prognostic approaches in this paper are compared according to their potential requirements in Table 5, where each requirement can be "Required", "Not required", and "Beneficial" for each prognostics approach.

Table 5: Prognostic approaches requirements.

\begin{tabular}{l|cccc}
\hline Approaches & \multicolumn{4}{|c}{ Engineering model Degradation history } \\
\hline Reliability & Not required & Required & Not required & Not required \\
\hline Similarity & Not required & Required & Required & Beneficial \\
\hline Model based & Required & Beneficial & Required & Required \\
\hline Data-driven & Not required & Beneficial & Required & Required \\
\hline
\end{tabular}

Table 6 presents a comparison between the four prognostics approaches in terms of precision, applicability, cost, and interpretability. For precision criteria, also component level and system level prognostic are compared for each prognostic approach, where $(+)$ refers to the advantage and (-) refers to the drawback of the methods.

Experience based approaches (Reliability and similarity) are easier to apply when degradation history is available, but less precise at system level prognostic due to the variability of operation and environment conditions. Degradation modelling approaches are divided into model based and data driven approaches. Model based prognostic may have a good precision at component level (i.e., crack 
Table 6: Prognostic approaches comparison.

\begin{tabular}{l|ccccc}
\hline Approaches & \multicolumn{2}{|c}{ Precision and applicability } & Implementation & Cost & Interpretability \\
& Component level System level & & & \\
\hline Reliability & + & - & ++ & -- & - \\
\hline Similarity & + & - & ++ & -- & - \\
\hline Model & ++ & + & - & - & + \\
\hline Data-driven & + & ++ & + & + & - \\
\hline
\end{tabular}

propagation of bearings). Although, when the system is more complex, this kind of approaches may not be precise or even applicable. Despite of the lack of interpretability of the data-driven approaches, they are the most suitable to perform the prognostic task of complex dynamic systems such as wind turbines.

Even with the increasing number of publications of fault prognostics for the predictive maintenance of WTs, several challenges still require to be addressed. Examples of these challenges are: how to ensure the prognostic when no a priori knowledge about the degradation behaviour is available (i.e., new installed system), which HI construction method is suitable for this case, the choose of the threshold value is also difficult and predicting the degradation evolution without a priori information about it is challenging.

The use of concept drift techniques can be an altenative solution to contribute addressing these challenges. They can be used in order to construct a HI and detect the drift from nominal conditions. When sufficient data about degradation is collected, the feature which fits the best the monotonicity and trendability during the degradation must be selected as HI. The threshold value must be chosen in order to detected the degradation as early as possible while avoiding the maximum of false alarms. In additions, multiple stage division should be considered in order to confirm the degradation occurrence. The degradation prediction model must also be updated with the collected incoming data in order to improve the performance of the prediction (precision). It is worth to mention that another challenge for fault prognostics is related to the RUL estimation for complex system due to the multiple interactions between their individual components. (see Fig. 3). Another challenge is related to the development of a post-prognostic phase in order to interpret prognostic results to the human operators by using a natural language.

\section{Acknowledgments}

This work is supported by the European Union - European Regional Development Fund. 


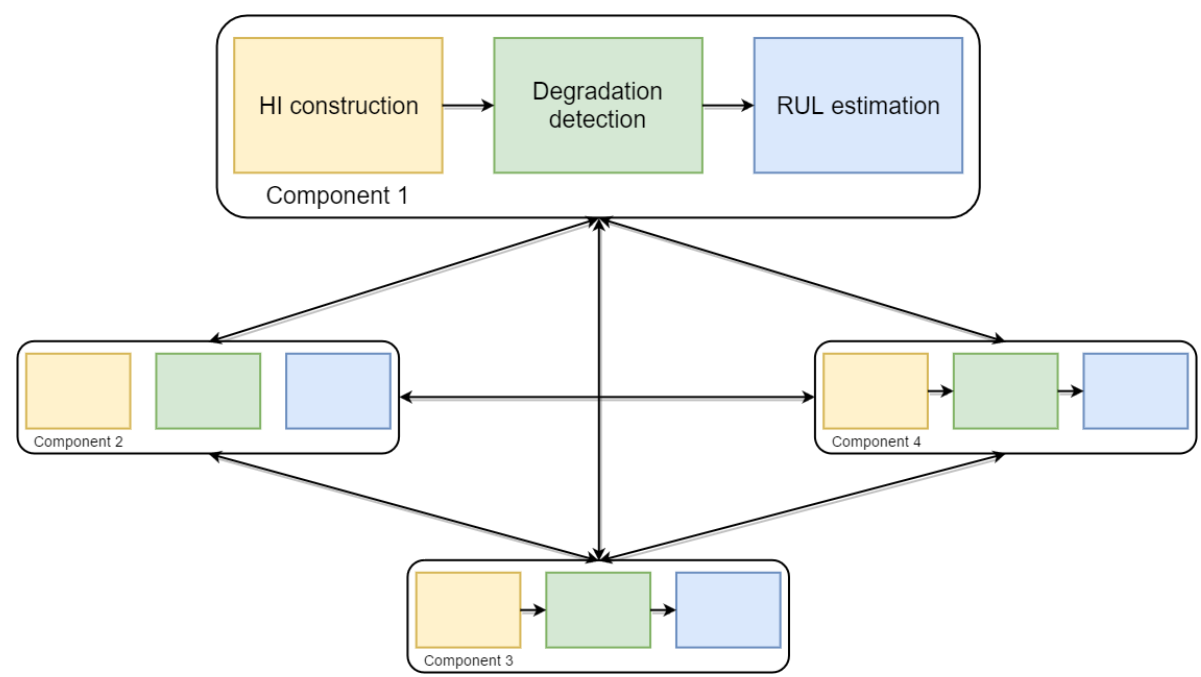

Fig. 3: Prognostic for complex system.

\section{References}

1. Annual combined onshore and offshore wind energy statistics. https://windeurope.org/about-wind/statistics/european/wind-in-power-2017, accessed: 2018-06-26

2. Bangalore, P., Tjernberg, L.B.: An artificial neural network approach for early fault detection of gearbox bearings. IEEE Transactions on Smart Grid 6(2), 980987 (2015)

3. Benkedjouh, T., Medjaher, K., Zerhouni, N., Rechak, S.: Remaining useful life estimation based on nonlinear feature reduction and support vector regression. Engineering Applications of Artificial Intelligence 26(7), 1751-1760 (2013)

4. Boškoski, P., Gašperin, M., Petelin, D., Juričić, .: Bearing fault prognostics using rényi entropy based features and gaussian process models. Mechanical Systems and Signal Processing 52, 327-337 (2015)

5. Cheng, F., Qu, L., Qiao, W.: Fault prognosis and remaining useful life prediction of wind turbine gearboxes using current signal analysis. IEEE Transactions on Sustainable Energy 9(1), 157-167 (2018)

6. Dupuis, R.: Application of oil debris monitoring for wind turbine gearbox prognostics and health management. In: Annual Conference of the prognostics and health management society. pp. 10-16 (2010)

7. Florian, M., Sørensen, J.D.: Wind turbine blade life-time assessment model for preventive planning of operation and maintenance. Journal of Marine Science and Engineering 3(3), 1027-1040 (2015)

8. Grujicic, M., Galgalikar, R., Ramaswami, S., Snipes, J., Chenna, V., Yavari, R.: Finite-element analysis of horizontal-axis wind-turbine gearbox failure via toothbending fatigue. Int. J. Mater. Mech. Eng 3, 6-15 (2014)

9. Javed, K., Gouriveau, R., Zerhouni, N., Nectoux, P.: Enabling health monitoring approach based on vibration data for accurate prognostics. IEEE Transactions on Industrial Electronics 62(1), 647-656 (2015) 
10. Kusiak, A., Zheng, H., Song, Z.: On-line monitoring of power curves. Renewable Energy 34(6), 1487-1493 (2009)

11. Lei, Y., Li, N., Guo, L., Li, N., Yan, T., Lin, J.: Machinery health prognostics: A systematic review from data acquisition to rul prediction. Mechanical Systems and Signal Processing 104, 799-834 (2018)

12. Lei, Y., Li, N., Lin, J.: A new method based on stochastic process models for machine remaining useful life prediction. IEEE Transactions on Instrumentation and Measurement 65(12), 2671-2684 (2016)

13. Malhi, A., Yan, R., Gao, R.X.: Prognosis of defect propagation based on recurrent neural networks. IEEE Transactions on Instrumentation and Measurement 60(3), 703-711 (2011)

14. Mosallam, A., Medjaher, K., Zerhouni, N.: Data-driven prognostic method based on bayesian approaches for direct remaining useful life prediction. Journal of Intelligent Manufacturing 27(5), 1037-1048 (2016)

15. Niu, G., Yang, B.S.: Intelligent condition monitoring and prognostics system based on data-fusion strategy. Expert Systems with Applications 37(12), 8831-8840 (2010)

16. Paris, P., Erdogan, F.: A critical analysis of crack propagation laws. Journal of basic engineering 85(4), 528-533 (1963)

17. Ramasso, E., Rombaut, M., Zerhouni, N.: Joint prediction of continuous and discrete states in time-series based on belief functions. IEEE transactions on cybernetics 43(1), 37-50 (2013)

18. Saidi, L., Ali, J.B., Bechhoefer, E., Benbouzid, M.: Wind turbine high-speed shaft bearings health prognosis through a spectral kurtosis-derived indices and svr. Applied Acoustics 120, 1-8 (2017)

19. Saxena, A., Celaya, J., Balaban, E., Goebel, K., Saha, B., Saha, S., Schwabacher, M.: Metrics for evaluating performance of prognostic techniques. In: Prognostics and health management, 2008. phm 2008. international conference on. pp. 1-17. IEEE (2008)

20. Sayed-Mouchaweh, M.: Learning from data streams in dynamic environments. Springer (2016)

21. Schömig, A.K., Rose, O.: On the suitability of the weibull distribution for the approximation of machine failures. In: IIE Annual Conference. Proceedings. p. 1. Institute of Industrial and Systems Engineers (IISE) (2003)

22. Soualhi, A., Medjaher, K., Zerhouni, N.: Bearing health monitoring based on hilbert-huang transform, support vector machine, and regression. IEEE Transactions on Instrumentation and Measurement 64(1), 52-62 (2015)

23. Tenenbaum, J.B., De Silva, V., Langford, J.C.: A global geometric framework for nonlinear dimensionality reduction. science 290(5500), 2319-2323 (2000)

24. Tobon-Mejia, D.A., Medjaher, K., Zerhouni, N., Tripot, G.: A data-driven failure prognostics method based on mixture of gaussians hidden markov models. IEEE Transactions on reliability 61(2), 491-503 (2012)

25. Toubakh, H., Sayed-Mouchaweh, M.: Hybrid dynamic data-driven approach for drift-like fault detection in wind turbines. Evolving Systems 6(2), 115-129 (2015)

26. Toubakh, H., Sayed-Mouchaweh, M.: Hybrid dynamic classifier for drift-like fault diagnosis in a class of hybrid dynamic systems: Application to wind turbine converters. Neurocomputing 171, 1496-1516 (2016)

27. Tse, P., Atherton, D.: Prediction of machine deterioration using vibration based fault trends and recurrent neural networks. Journal of vibration and acoustics 121(3), 355-362 (1999) 
28. Uluyol, O., Parthasarathy, G., Foslien, W., Kim, K.: Power curve analytic for wind turbine performance monitoring and prognostics. In: Annual conference of the prognostics and health management society. vol. 2, pp. 1-8 (2011)

29. Wang, P., Youn, B.D., Hu, C.: A generic probabilistic framework for structural health prognostics and uncertainty management. Mechanical Systems and Signal Processing 28, 622-637 (2012)

30. Wang, T., Yu, J., Siegel, D., Lee, J.: A similarity-based prognostics approach for remaining useful life estimation of engineered systems. In: Prognostics and Health Management, 2008. PHM 2008. International Conference on. pp. 1-6. IEEE (2008)

31. Wang, W.Q., Golnaraghi, M.F., Ismail, F.: Prognosis of machine health condition using neuro-fuzzy systems. Mechanical Systems and Signal Processing 18(4), 813$831(2004)$

32. Wang, Y., Ma, X., Joyce, M.J.: Reducing sensor complexity for monitoring wind turbine performance using principal component analysis. Renewable energy 97, 444-456 (2016)

33. Wang, Y., Peng, Y., Zi, Y., Jin, X., Tsui, K.L.: A two-stage data-driven-based prognostic approach for bearing degradation problem. IEEE Transactions on Industrial Informatics 12(3), 924-932 (2016)

34. Yan, J., Koc, M., Lee, J.: A prognostic algorithm for machine performance assessment and its application. Production Planning \& Control 15(8), 796-801 (2004)

35. Zhai, L.Y., Lu, W.F., Liu, Y., Li, X., Vachtsevanos, G.: Analysis of time-to-failure data with weibull model in product life cycle management. In: Re-engineering manufacturing for sustainability, pp. 699-703. Springer (2013)

36. Zhang, B., Zhang, L., Xu, J.: Degradation feature selection for remaining useful life prediction of rolling element bearings. Quality and Reliability Engineering International 32(2), 547-554 (2016)

37. Zhu, J., Yoon, J., He, D., Qiu, B., Bechhoefer, E.: Online condition monitoring and remaining useful life prediction of particle contaminated lubrication oil. In: Prognostics and Health Management (PHM), 2013 IEEE Conference on. pp. 1-14. IEEE (2013)

38. Zhu, J., Yoon, J.M., He, D., Qu, Y., Bechhoefer, E.: Lubrication oil condition monitoring and remaining useful life prediction with particle filtering. International Journal of Prognostics and Health Management 4, 124-138 (2013)

39. Zio, E., Di Maio, F.: A data-driven fuzzy approach for predicting the remaining useful life in dynamic failure scenarios of a nuclear system. Reliability Engineering \& System Safety 95(1), 49-57 (2010)

40. Zio, E., Peloni, G.: Particle filtering prognostic estimation of the remaining useful life of nonlinear components. Reliability Engineering \& System Safety 96(3), 403409 (2011) 